\title{
EAACI Task force Clinical epidemiology of anaphylaxis: experts' perspective on the use of adrenaline autoinjectors in Europe
}

\author{
Magdalena Kraft ${ }^{1}$, Sabine Dölle-Bierke ${ }^{1}$, Paul J. Turner ${ }^{2}$, Antonella Muraro ${ }^{3}$, Montserrat Fernández-Rivas ${ }^{4}$, \\ Linus Grabenhenrich ${ }^{1,5}$ and Margitta Worm ${ }^{1 *}$
}

\begin{abstract}
Background: Worldwide, guidelines recommend the use of adrenaline autoinjectors (AAls) for self-medication in patients who experience severe allergic reaction. The European Medical Agency recommends the prescription of two AAls, which should be carried by patients at all times. The European Academy of Allergy and Clinical Immunology guidelines propose to prescribe a second AAl under some defined conditions. In the present study, we aimed to examine the adherence to these guidelines and prescription behavior of allergy experts regarding the number of AAls prescribed for a given patient.
\end{abstract}

Methods: A standardized questionnaire was applied to the participants of the 5th International Conference of the Network of Online Registration for Anaphylaxis (NORA e. V.). Twenty-six experts (medical doctors with at least 2 years of experience in the field of anaphylaxis) answered the questions regarding the number of autoinjectors prescribed and the reasons influencing their decisions.

Results: Sixty-eight percent of the experts usually prescribed one AAl, while 32\% prescribed two. The pediatricians and physicians with less experience tended to prescribe two autoinjectors more frequently. The experts were more likely to prescribe two adrenaline autoinjectors if the patient was a child, had a previous severe reaction, had mastocytosis, asthma, cardiovascular disease, or high body weight, or lived far from the emergency department.

Conclusion: Our data confirm the lack of consensus regarding the number of AAls to prescribe. Despite the European Medical Agency recommendation, the majority of allergy experts prescribed one autoinjector per patient. However, under distinct circumstances (e.g. mastocytosis, asthma, excess body weight, a history of severe anaphylaxis, or restricted access to immediate emergency), experts tended to prescribe more AAls, which is in accordance with the European Academy of Allergy and Clinical Immunology guidelines.

Keywords: Anaphylaxis, Anaphylactic reaction, Adrenaline autoinjector, AAl, Epinephrine autoinjector, European Academy of Allergy and Clinical Immunology guidelines, European Medical Agency

*Correspondence: margitta.worm@charite.de

${ }^{1}$ Division of Allergy and Immunology, Dpt. of Dermatology, Venerology and Allergology, Charité - Universitätsmedizin Berlin Corporate Member of Freie Universität Berlin, Humboldt-Universität zu Berlin, and Berlin Institute of Health, Berlin, Germany

Full list of author information is available at the end of the article

\section{Background}

Globally, guidelines recommend the use of adrenaline autoinjectors (AAIs) for self-medication in patients who experience severe allergic reaction [1-3]. However, previous data from the European Anaphylaxis Registry (Network of Online Registration for Anaphylaxis (NORA e. V.)) has shown that the use of AAI by patients (or their carers) is low, and remains low

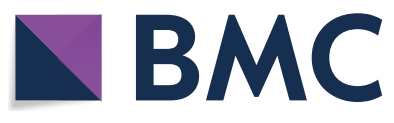

(c) The Author(s) 2020. This article is licensed under a Creative Commons Attribution 4.0 International License, which permits use, sharing, adaptation, distribution and reproduction in any medium or format, as long as you give appropriate credit to the original author(s) and the source, provide a link to the Creative Commons licence, and indicate if changes were made. The images or other third party material in this article are included in the article's Creative Commons licence, unless indicated otherwise in a credit line to the material. If material is not included in the article's Creative Commons licence and your intended use is not permitted by statutory regulation or exceeds the permitted use, you will need to obtain permission directly from the copyright holder. To view a copy of this licence, visit http://creativeco mmons.org/licenses/by/4.0/. The Creative Commons Public Domain Dedication waiver (http://creativecommons.org/publicdomain/ zero/1.0/) applies to the data made available in this article, unless otherwise stated in a credit line to the data. 
despite the implementation of educational initiatives [4]. The European Medical Agency (EMA) recommends the prescription of two AAIs, which should be carried by patients at all times [5]. This is also reflected in existing European guidelines, where specific scenarios are listed when prescribers should consider the need to provide a second AAI [1]. Such factors include coexisting unstable or moderate-to-severe persistent asthma and a food allergy, mast cell diseases and elevated baseline tryptase, lack of access to emergency medical services, previous reaction requiring more than one dose of adrenaline, previous near fatal anaphylaxis, and lastly, if the available AAI dose is too low with respect to body weight. These recommendations are based on data which have shown that a single dose of adrenaline is not always sufficient to control an anaphylaxis $[1,2$, 6-8]. However, the evidence grade for these recommendations is low (IV or V).

In the present study we performed a questionnairebased analysis of the AAI prescription behavior among participants of the 5th International Conference of NORA e. V. We sought to investigate how experts from specialized tertiary allergy centers vary in their daily practice regarding the number of AAI prescribed, and which factors influence their decisions.

\section{Methods}

Allergy centers throughout Europe can participate in the NORA e. V. and contribute to the Anaphylaxis Registry. The biennial international conference is held to exchange knowledge and data gained within and outside the network regarding anaphylaxis. During the conference the European Academy of Allergy and Clinical Immunology (EAACI) task force on the implementation of guidelines in anaphylaxis is having a meeting. The 5th International Conference was held in April 2019. Forty-five experts participated in the conference; data was collected from 26 attendees who were medical doctors with at least 2 years of experience in the field of anaphylaxis using a questionnaire (Additional file 1). The demographic data of this study population is presented in Fig. 1. Seventynine percent of the experts were females $(n=19$, Fig. 1a). The median experience in the field of anaphylaxis was 8.5 years (Fig. 1b). Attendees came from 10 different countries (Fig. 1c), and represented a range of medical specialties (Fig. 1d, multiple selection possible) including allergology and pediatric allergology $(n=20)$, pediatrics $(n=12)$, dermatology $(n=6)$, and internal medicine $(\mathrm{n}=2)$. The data were analyzed using STATA ${ }^{\circledR} 15.0$ statistical software (Stata Corp., College Station, Texas).

\section{a}

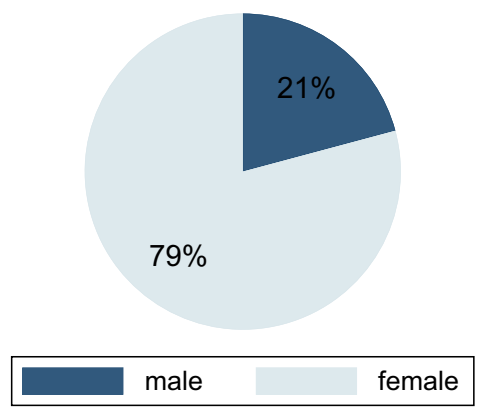

C

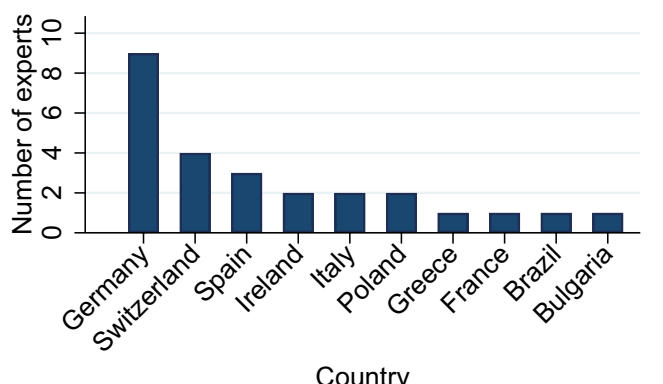

b

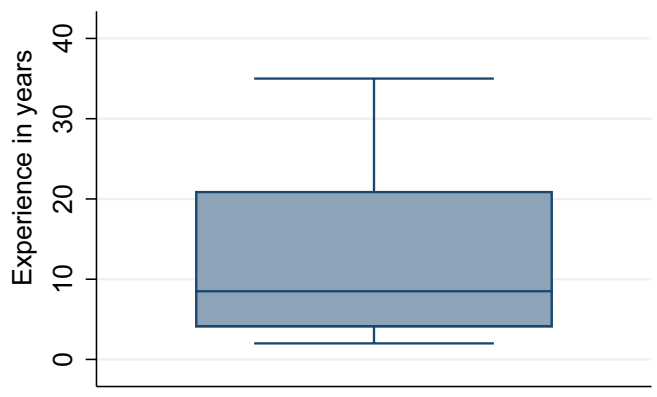

d

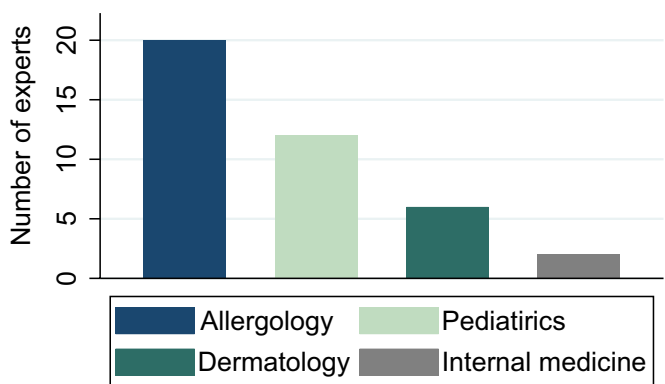

Fig. 1 Demographic characteristic of the study population regarding gender (a), experience in the field of anaphylaxis (b), country (c) and medical specialty (d) 


\section{Results}

AAI prescription behavior among allergists from NORA

Sixty-eight percent of the experts $(n=17)$ described their usual practice as prescribing one AAI and $32 \%(n=9)$ prescribed two AAIs (Fig. 2a) in usual. The younger physicians and pediatricians tended to prescribe more frequently two autoinjectors for one patient (Fig. 2b, c).

\section{Factors influencing the AAI prescription behavior}

To investigate factors which might influence prescription decisions, participants were asked to complete on a visual analogue scale the degree to which a given factor might influence their decision to prescribe one (left end of the visual scale) or more than one (right end of the visual scale) AAI. Figure 3 summarizes the results in form of violin plots for each item. Respondents tended to prescribe $>1$ AAI if the patient was a child (Fig. 3a) or had a history of prior severe anaphylaxis reaction (Fig. 3c). Elicitors (food vs. insect) was not an important factor (Fig. 3b), while mastocytosis, asthma or cardiovascular diseases as comorbidity was. In addition, if the patient lived far from the emergency department, s/he would be more likely to be prescribed two AAIs (Fig. 3d).

We then asked respondents as to whether their decision was influenced by legal and/or economic considerations
(Fig. 4). Forty-four percent of them $(n=11)$ responded that their decisions were influenced by regulatory aspects, $52 \%(\mathrm{n}=13)$ by reimbursement issues, and $72 \%$ by the availability of AAI in the community. However, when asked if the shortage of AAIs in the previous months (this survey was performed in April 2019) had an impact on their prescription habits, most of the experts $(58 \%, \mathrm{n}=16)$ denied this (data not shown).

\section{Discussion}

Limited data exists regarding the implementation of guidelines on the prescription of AAI in Europe. Recent data from the EAACI revealed that only $59 \%$ of the allergists who answered a single questionnaire were following these recommendations (unpublished data). Data from the Anaphylaxis Registry show that $35 \%$ of patients with a history of anaphylaxis treated in tertiary allergy centers were prescribed more than one AAI [9]. Our data confirm the lack of consensus regarding the number of AAIs to prescribe, although following the EAACI guidelines [1], experts tended to prescribe more AAIs if the patient had mastocytosis, asthma, excess body weight, a history of severe anaphylaxis, or restricted access to immediate emergency treatment (Fig. 3). Children were more frequently prescribed $>1 \mathrm{AAI}$, which is consistent with data

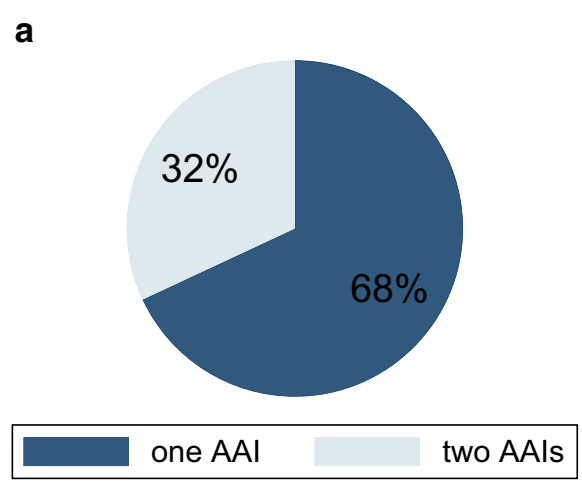

C
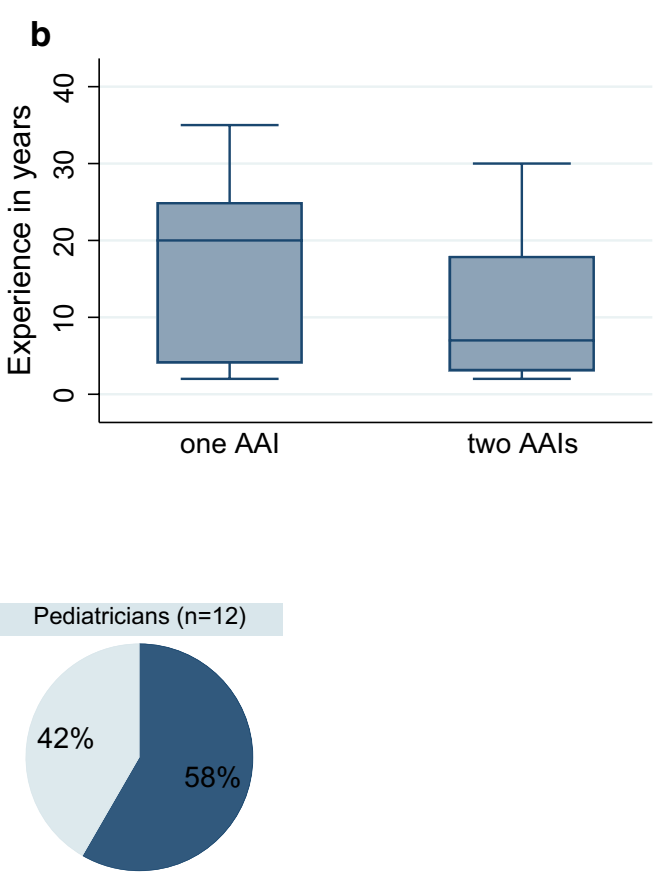

one AAl two AAls

Fig. 2 Proportion of experts $(n=26)$ who prescribe usually one or two adrenaline autoinjectors per one patient in total (a) and separate for pediatricians and non-pediatricians (c). The distribution of experience years in the field of anaphylaxis in the group of experts who usually prescribe one and in the group who usually prescribe two autoinjectors (b) 


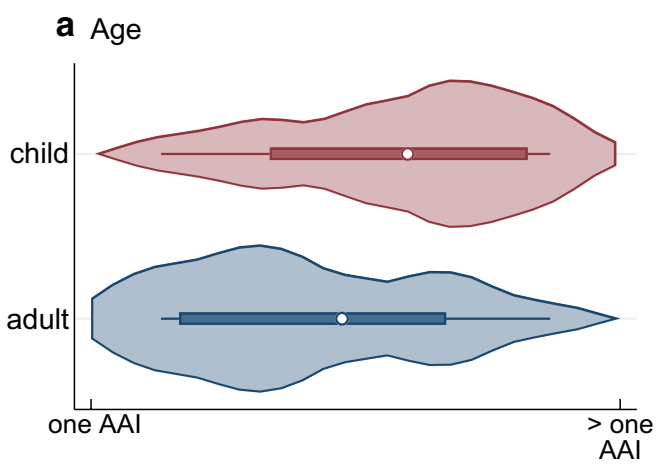

C Severity of the previous reaction

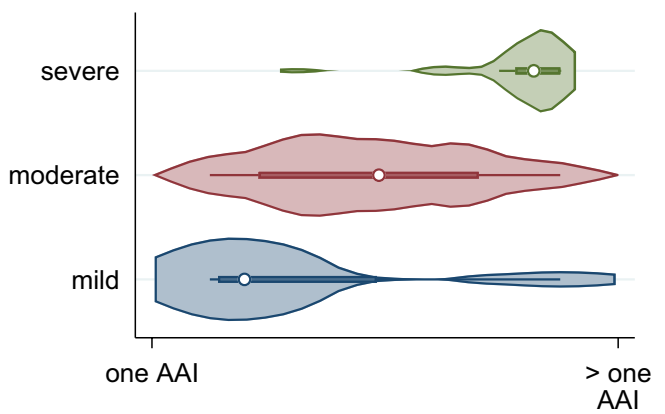

b Elicitor of the prevoius reaction

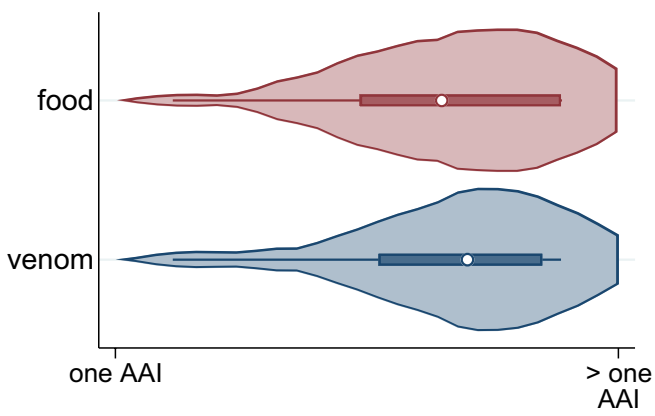

d Other factors

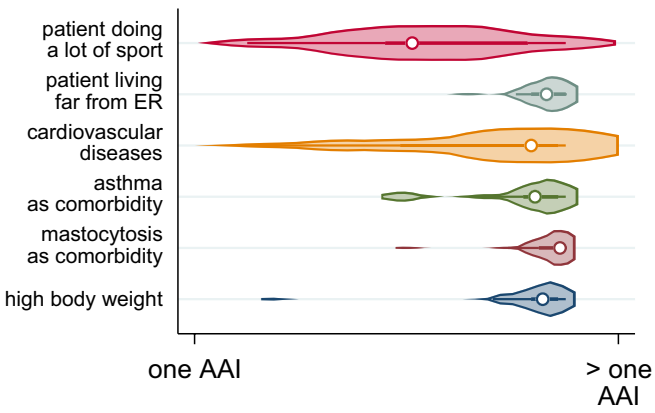

Fig. 3 Factors influencing the AAl prescription behavior. The violin plots indicate if the given factor: age (a), elicitor (b), severity (c) or other factors (d) would influence the experts to prescribe one (left end of the scale) or more than one (right end of the scale) autoinjectors

form the Anaphylaxis Registry in which 50\% of children were prescribed $>1$ AAI compared with $\sim 30 \%$ of adults [9]. There are significant geographical factors involved, as up to $92 \%$ children are prescribed $2+$ AAIs in the UK, although this is likely to be a combination of children being prescribed one AAI for personal use and a separate AAI for school [10]. An additional factor could be the strong recommendation by the UK regulator to prescribe 2 AAIs (which are free in the UK to children) to be carried at all times.

We only partially examined the reasons behind experts' decision to prescribe a single AAI. The regulatory and reimbursement aspects appear to play a role in approximately half of the experts. Other key barriers may be: high cost of devices, doubts regarding patients' compliance to carry and use two AAIs, the belief that the second adrenaline dose will not be required, or a low evidence grade for the recommendation in the guidelines. For these reasons, we conclude that, measures to lower the costs of AAIs and more data supporting EMA recommendations are needed to increase the rate of patients being prescribed a second adrenaline dose.

The main limitation of our analysis is the small survey size. The survey was performed during the specialized allergology conference which took place in Germany and was associated with EAACI Task force Clinical epidemiology of anaphylaxis meeting, so the German experts and members of the Task force were overrepresented which may have biased the results. The second important limitation is the fact, that only a few questions examining the reasons for experts' prescription habits were asked, which makes a more in-depth analysis of that important question not possible.

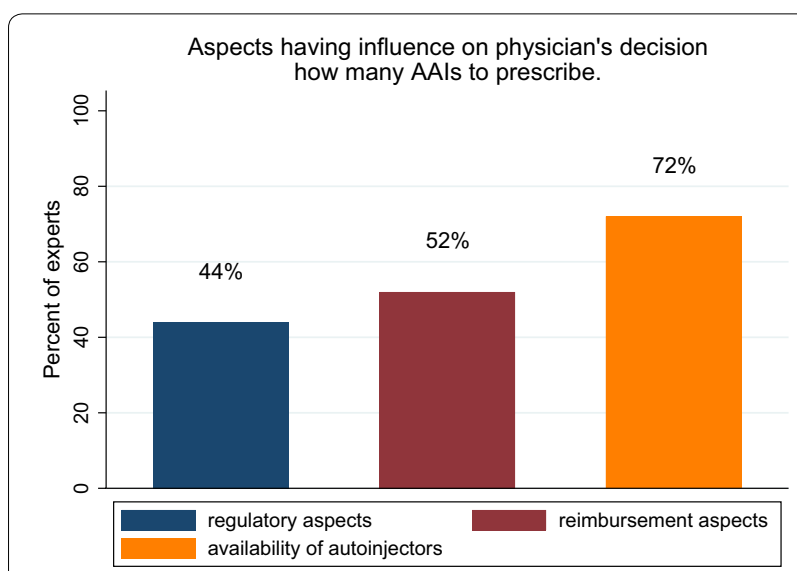

Fig. 4 Proportions of experts being influenced by regulatory, reimbursement and availability aspects in their decision regarding number of AAls per one patient 


\section{Conclusions}

Our data point out discrepancies even among specialists and indicate a need for a larger, representative survey among physicians form different European countries and wider medical specialties treating anaphylaxis patients. More detailed questions on the training and experience in the field of anaphylaxis and reasons for decision making should be asked. EAACI and other medical societies could be used as a platform to reach the physicians. The results of this survey could provide an important perspective which should be taken into consideration during guidelines development, decision making by regulatory health agencies and the development of standardized trainings for young physicians.

\section{Supplementary information}

Supplementary information accompanies this paper at https://doi. org/10.1186/s13601-020-00317-y.

Additional file 1. Questionnaire.

\section{Abbreviations}

AAl: Adrenaline autoinjector; EAACl: European Academy of Allergy and Clinical Immunology; EMA: European Medical Agency; NORA: Network of Online Registration for Anaphylaxis.

\section{Acknowledgements}

We thank the participants of 5th international conference of the network of online registration for anaphylaxis (NORA e. V.) for participating in this study. We thank V. Bialas for data entry. We thank EAACI Task force Clinical epidemiology of anaphylaxis and NORA e. V. for supporting our project.

\section{Authors' contributions}

MK created the design of the study, managed data acquisition, performed data analysis and wrote the manuscript. SDB, PJT, AM, MFR and LG contributed to the interpretation of data and revised the manuscript critically for important intellectual content. MW created the conception and the design of the study, managed data acquisition, contributed to the interpretation of data, and revised the manuscript critically. All authors read and approved the final manuscript.

\section{Funding}

The open access publication of this article (article processing charge) was supported by EAACI.

\section{Availability of data and materials}

The dataset generated and analyzed during the current study are not publicly available due to data protection but are available from the corresponding author on reasonable request (excluding personal data).

\section{Ethics approval and consent to participate}

Not applicable.

\section{Consent for publication \\ Not applicable.}

\section{Competing interests}

MW served as a consultant and received speaker honoraria from Mylan Germany, ALK-Abelló, Allergopharma, outside the submitted work. AM received speaker's honoraria from Aimmune, DVB, Nestlè-Purina, Nutricia, Mylan, outside the submitted work. MFR reports personal fees form Aimmune, Allergy Therapeutics, ALK-Abelló, DBV, Diater, HAL Allergy and grants from Aimmune, outside the submitted work. MK, LG, SDB and PJT declare that they have no relevant conflicts of interest.

\section{Author details}

${ }^{1}$ Division of Allergy and Immunology, Dpt. of Dermatology, Venerology and Allergology, Charité - Universitätsmedizin Berlin Corporate Member of Freie Universität Berlin, Humboldt-Universität zu Berlin, and Berlin Institute of Health, Berlin, Germany. ${ }^{2}$ Section of Inflammation, Repair \& Development, National Heart \& Lung Institute, Imperial College London, London, UK. ${ }^{3}$ Food Allergy Referral Centre, Department of Women and Child Health, Padua General University Hospital, Padua, Italy. ${ }^{4}$ Department of Allergy, Hospital Clinico San Carlos, Universidad Complutense, IdISSC, ARADyAL, Madrid, Spain.

${ }^{5}$ Department for Infectious Disease Epidemiology, Robert Koch-Institut, Berlin, Germany.

Received: 12 March 2020 Accepted: 13 April 2020

Published online: 11 May 2020

\section{References}

1. Muraro A, Roberts G, Worm M, Bilo MB, Brockow K, Fernandez Rivas M, et al. Anaphylaxis: guidelines from the European Academy of Allergy and Clinical Immunology. Allergy. 2014;69(8):1026-45.

2. Simons FE, Ardusso LR, Bilo MB, El-Gamal YM, Ledford DK, Ring J, et al. World allergy organization guidelines for the assessment and management of anaphylaxis. World Allergy Organ J. 2011;4(2):13-37.

3. Ring J, Beyer K, Biedermann T, Bircher A, Duda D, Fischer J, et al. Guideline for acute therapy and management of anaphylaxis: S2 Guideline of the German Society for Allergology and Clinical Immunology (DGAKI), the Association of German Allergologists (AeDA), the Society of Pediatric Allergy and Environmental Medicine (GPA), the German Academy of Allergology and Environmental Medicine (DAAU), the German Professional Association of Pediatricians (BVKJ), the Austrian Society for Allergology and Immunology (OGAI), the Swiss Society for Allergy and Immunology (SGAI), the German Society of Anaesthesiology and Intensive Care Medicine (DGAI), the German Society of Pharmacology (DGP), the German Society for Psychosomatic Medicine (DGPM), the German Working Group of Anaphylaxis Training and Education (AGATE) and the patient organization German Allergy and Asthma Association (DAAB). Allergo J Int. 2014;23(3):96-112.

4. Grabenhenrich LB, Dolle S, Rueff F, Renaudin JM, Scherer K, Pfohler C, et al. Epinephrine in Severe Allergic Reactions: the European Anaphylaxis Register. J Allergy Clin Immunol Pract. 2018;6(6):1898-906.

5. Lieberman P, Nicklas RA, Randolph C, Oppenheimer J, Bernstein D, Bernstein J, et al. Anaphylaxis-a practice parameter update 2015. Ann Allergy Asthma Immunol. 2015;115(5):341-84.

6. Pumphrey RS. Lessons for management of anaphylaxis from a study of fatal reactions. Clin Exp Allergy. 2000;30(8):1144-50.

7. Song TT, Brown D, Karjalainen M, Lehnigk U, Lieberman P. Value of a second dose of epinephrine during anaphylaxis: a patient/caregiver survey. J Allergy Clin Immunol Pract. 2018;6(5):1559-67.

8. Simons FE. First-aid treatment of anaphylaxis to food: focus on epinephrine. J Allergy Clin Immunol. 2004;113(5):837-44.

9. Kraft M, Knop M, Renaudin JM, Scherer Hofmeier K, Pfohler C, Bilo MB, et al. Secondary prevention measures in anaphylaxis patients: data from the Anaphylaxis Registry. Allergy. 2019. https://doi.org/10.1111/all.14069.

10. Diwakar L, Cummins C, Ryan R, Marshall T, Roberts T. Prescription rates of adrenaline auto-injectors for children in UK general practice: a retrospective cohort study. Br J Gen Pract. 2017;67(657):e300-5.

\section{Publisher's Note}

Springer Nature remains neutral with regard to jurisdictional claims in published maps and institutional affiliations. 